\title{
Pemanfaatan limbah piston bekas sebagai filler metal aluminium pada pengelasan oxy-acetylene
}

\section{Z. Nurisna}

Teknik Mesin Program Vokasi Universitas Muhammadiyah Yogyakarta, Jln. Lingkar Selatan Tamantirto, Kasihan, Bantul, Daerah Istimewa Yogyakarta Kode Pos : 55185, Telp. (0274) 387656 Ext. 265 Fax (0274) 387646.

*Email: zuhrinurisna@umy.ac.id

\section{ARTICLE INFO}

Article History:

Received February 2017

Accepted October 2017

Available online 30 December 2017

Keywords:

Limbah piston

Filler metal

Oxy-acetylene welding

In cooperation with SNMI XI 2017

Special Edition

\section{ABSTRACT}

The abundance of waste piston used so far has not been utilized properly. Users of this piston waste can be used as an oxyacetylene welder filler. Las oxy-acetylene has been widely used for welding on various types of aluminum product repair, one of which is welding machine block. Machine blocks in their use often suffered damage to the cooling water circulation path and broken crack and broken. Welders and repair shops that repair these damages do not have standardized standards in the use of weld fillers, but they do filler selection based solely on experience including in determining the weld filler. The purpose of this research is to know the effect of piston waste which is used as raw material of weld filler to tensile strength and hardness of welded block result of machine using oxy-acetylene welding. Welding is done by an experienced welder. The welding results are tested for tensile strength and hardness distribution test. The welded joint with the chemical composition of filler which is almost equal to base metal has the highest tensile strength. The tensile strength of the welded joint tension test is in the weld metal region due to defects in the weld metal, especially the porosity defects that are formed during the welding process so that the tensile test loading is concentrated on the defect. While the highest hardness on the weld is in the filler metal with the highest percentage of Si content.

\section{PENDAHULUAN}

Perkembangan teknologi di bidang otomotif semakin pesat, diantaranya penggunaan material yang lebih ringan, kuat, dan tahan korosi sebagai pengganti material sebelumnya. Salah satu usaha produsen kendaraaan untuk meningkatkan performa produknya adalah dengan mengganti material blok mesin. Penggunaan blok mesin aluminium dimulai pada mesin bensin pada akhir tahun 1970. Pertengahan tahun 1990 pembuatan blok mesin diesel mulai mengalami pergantian material dari besi cor menjadi alumunium, hal tersebut dikarenakan material aluminium yang lebih ringan dan bertujuan untuk mengurangi berat blok mesin diesel. Tahun 2005 penggunaan blok mesin aluminium terus meningkat hingga mencapai $50 \%$ dari pangsa pasar dan terus meningkat. Saat ini blok mesin terbuat dari aluminium dan aluminium paduan. Aplikasi material ini juga sangat berkembang dalam 
pembuatan blok mesin diesel (European Aluminium Association, 2011).

Dalam proses perbaikan blok mesin biasanya menggunakan bahan logam tambahan (filler) sebagai logam pengisi antara logam induk yang dilas. Penggunaan filler ini dimaksudkan sebagai pengisi logam yang hilang dalam kerusakan blok mesin karena patahan yang hilang maupun blok mesin yang rusak karena abrasi oleh air radiator. Pengunaan filler memiliki pengaruh terhadap karakterisai sifat fisik-mekanik hasil lasan (Sudargo dkk., 2011).

Pengelasan perbaikan blok mesin memerlukan suatu proses pengelasan yang dapat melebur dan menghilangkan lapisan $\mathrm{Al}_{2} \mathrm{O}_{3}$ beserta kerak dari permukaan blok mesin yang akan dilas dengan cara mencairkan aluminium dibawah lapisan $\mathrm{Al}_{2} \mathrm{O}_{3}$ dan mengangkat lapisan $\mathrm{Al}_{2} \mathrm{O}_{3}$ tersebut. Hal ini sulit dilakukan dengan menggunakan metode pengelasan lainnya. Proses perbaikan blok mesin ini dalam prakteknya menggunakan las Oxy-acetylene Welding (OAW). Dipilihnya las OAW karena keluaran panas dari pengelasan dapat dikontrol dengan mudah sehingga sebelum ditambahkan filler pada logam induk, lapisan $\mathrm{Al}_{2} \mathrm{O}_{3}$ dan kerak pada permukaan blok mesin dapat dihilangkan dengan pencairan pada lapisan permukaan blok mesin (Turan and Ünlungencoglu, 2011).

Refrensi ilmiah perbaikan blok mesin dengan las OAW sangat minim, sehingga pelaksanaan perbaikan blok mesin tersebut mengandalkan pengalaman operator. Dalam prakteknya terdapat beberapa material yang digunakan sebagai filler antara lain dari limbah piston bekas bus yang sudah tidak terpakai. Pemilihan jenis filler ini pada prakteknya hanya berdasarkan pengalaman operator tanpa didasari landasan ilmiah. Karena blok mesin merupakan bagian yang penting pada suatu kendaraan maka dibutuhkan refrensi ilmiah, sehingga penelitian perbaikan blok mesin perlu dilakukan.

Las Oxy-acetylene (las asetilin) adalah proses pengelasan secara manual, dimana permukaan yang akan disambung mengalami pemanasan sampai mencair oleh nyala (flame) gas asetilin (yaitu pembakaran $\mathrm{C}_{2} \mathrm{H}_{2}$ dengan $\mathrm{O}_{2}$ ), dengan atau tanpa logam pengisi, dimana proses penyambungan tanpa penekanan. Disamping untuk keperluan pengelasan (penyambungan) las gas dapat juga dipergunakan sebagai : preheating, brazing, cutting dan hard facing. Penggunaan untuk produksi (production welding), pekerjaan lapangan (field work), dan reparasi (repair \& maintenance).

Seperangkat las Oxy-acetylene terdiri dari satu tabung oksigen, satu tabung acetylene, satu unit selang gas, satu uni regulator, dan brander. Tabung gas digunakan untuk menampung gas, regulator digunakan untuk mengetahui isi tabung dan mengatur tekanan tabung, selang gas untuk menyalurkan gas dari tabung ke brander, serta brander digunakan sebagai alat pencampur gas oksigen dan acetylene seperti terlihat pada Gambar 1.

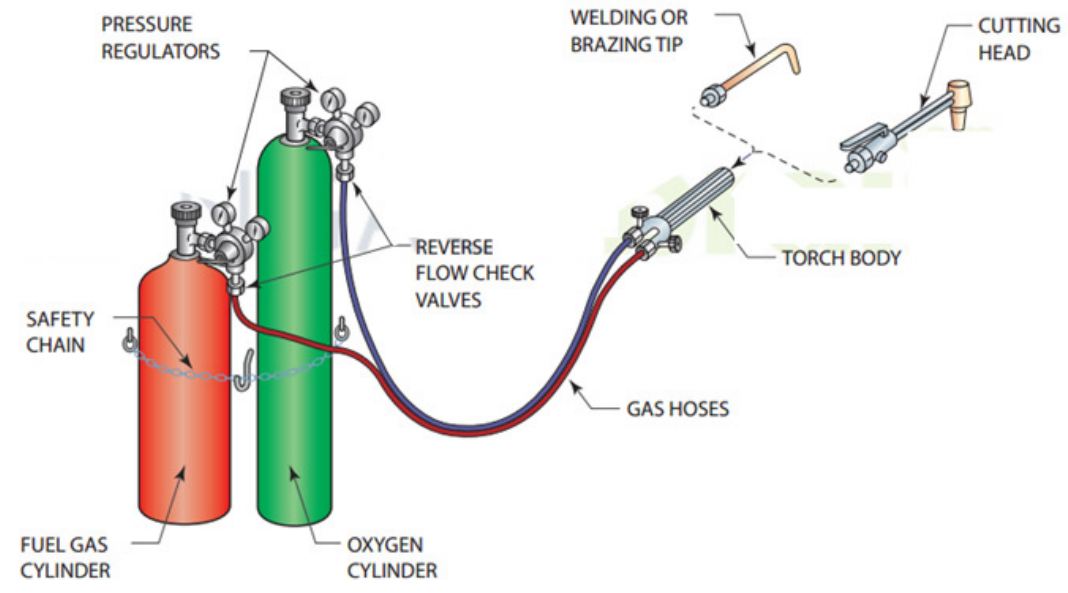

Gambar 1. Seperangkat peralatan las oxy-acetylene (Jeffus, 2012). 


\section{METODE PENELITIAN}

\section{Bahan penelitian}

Bahan yang digunakan dalam penelitian ini yaitu blok mesin mobil sebagai objek yang dilas dan limbah piston bus Mitsubishi, Hino dan
Mercedes Benz yang digunakan sebagai filler pengelasan. Keempat bahan tersebut ditunjukkan dalam Gambar 2 dan hasil pengujian komposisi kimia ditunjukkan pada Tabel 1.

Tabel 1. Hasil uji komposisi material blok mesin dan filler.

\begin{tabular}{|c|c|c|c|c|c|c|c|c|}
\hline Material & $\mathrm{Al}$ & $\mathrm{Si}$ & $\mathrm{fe}$ & $\mathrm{Cu}$ & $\mathrm{Mn}$ & $\mathrm{Mg}$ & $\mathrm{Cr}$ & $\mathrm{Ni}$ \\
\hline $\begin{array}{c}\text { Blok Colt } \\
\text { T 120 }\end{array}$ & 90,79 & 6,35 & 0,79 & 0,954 & 0,638 & $<0,05$ & $<0,01$ & 0,044 \\
\hline $\begin{array}{c}\text { Piston } \\
\text { Hino }\end{array}$ & 86,04 & 10,8 & 0,75 & 1,18 & 0,031 & $<0,05$ & $<0,01$ & $<0,02$ \\
\hline $\begin{array}{c}\text { Piston } \\
\text { Mitsubishi }\end{array}$ & 86,17 & 10,9 & 0,75 & 1,08 & 0,023 & $<0,05$ & $<0,01$ & $<0,02$ \\
\hline $\begin{array}{c}\text { Piston } \\
\text { Mercedes }\end{array}$ & 86,04 & 10,6 & 0,75 & 1,26 & 0,024 & $<0,05$ & $<0,01$ & $<0,02$ \\
\hline
\end{tabular}
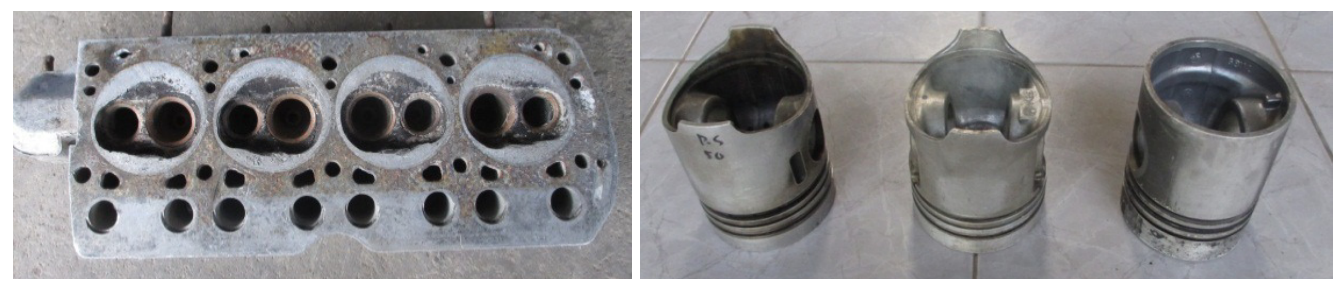

Gambar 2. Bahan blok mesin dan limbah piston.
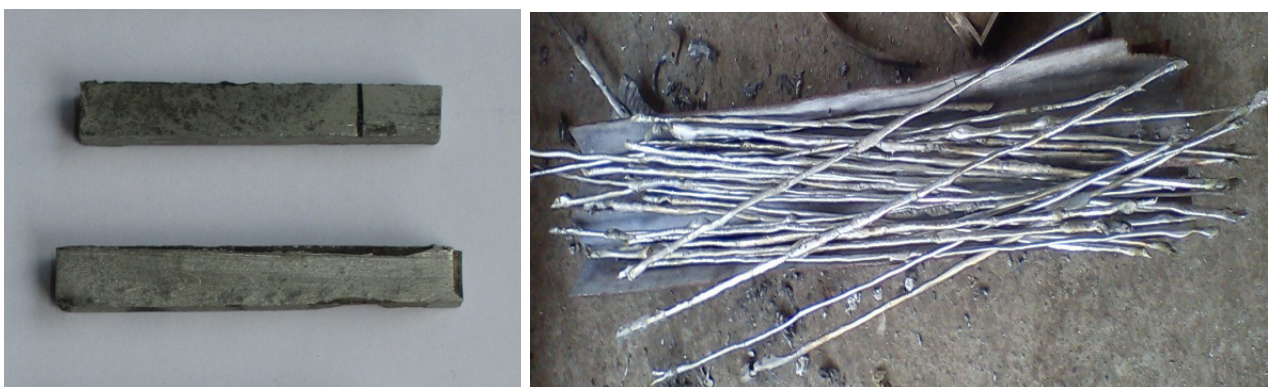

Gambar 3. Blok mesin yang telah dipotong

\section{Pengelasan}

Pengelasan blok mesin didahului dengan persiapan pembuatan filler dari limbah piston bus. Proses pembuatan filler tersebut dilakukan dengan cara sebagai berikut :

1. Menyiapkan cetakan yang akan digunakan untuk mencetak filler.

2. Menyalakan las OAW dan menyetel nyala las menjadi nyala oksidasi.

3. Memegang piston bekas yang akan dilebur dengan menggunakan tang.

4. Mengarahkan las dengan nyala oksidasi tersebut pada piston bekas diatas cetakan yang telah disedikan.
Bahan blok mesin yang telah dipotong, kemudian dilas menggunakan las OAW dengan filler yang telah divariasikan dari limbah piston bus Mercedes Benz, Mitsubishi, Hino. Proses pengelasan dilakukan oleh welder yang sudah berpegalaman dalam pengelasan las $O x y$ acetylene, blok aluminium yang sudah dipotong sesuai standar JIS dilakukan pengelasan dengan cara sebagai berikut :

1. Menyiapkan dua potongan blok mesin yang telah di potong, dan filler dari limbah piston yang sebelumnya sudah dilebur menjadi batangan seperti yang ditunjukkan pada gambar 3. 
2. Mengatur jarak potongan blok mesin sebesar 1 $\mathrm{mm}$ sejajar dengan arah pengelasan.

3. Menyalakan las OAW dan menyetel nyala las menjadi nyala oksidasi.

4. Melakukan pengelasan dengan menggunakan filler dari limbah piston bus Mercedes Benz seperti pada Gambar 4.

5. Mengulangi langkah 2 sampai langkah 4 menggunakan filler dari piston bus Mitsubishi, dan piston bus Hino.

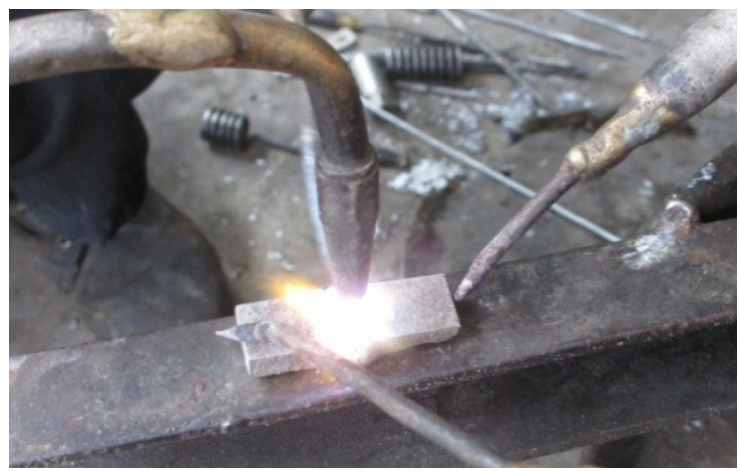

Gambar 4. Proses pengelasan

\section{Pengujian hasil lasan}

Pengujian tarik hasil lasan menggunakan alat Universal Testing Machine (UTM) dengan menggunakan standar JIS Z 2201 seperti terlihat pada Gambar 5. (Diameter : $5 \mathrm{~mm}$, Lo : $40 \mathrm{~mm}, \mathrm{P}$ : $50 \mathrm{~mm}$ ). menggunakan standar JIS Z 22019.

Sedangkan pengujian

kekerasan menggunakan alat micro vickers dengan menggunakan standart ASTM E 92. Pengukuran kekerasan dilakukan pada penampang melintang material hasil las oxy-acetylene. Pengujian kekerasan ini dilakukan untuk menguji distribusi kekerasan pada base metal, daerah $H A Z$, dan weld metal. Pengujian mikro Vickers dengan menggunakan penekan berbentuk piramida intan, beban yang dipergunakan adalah 100 gf dengan lama penekanan 10 detik dan jarak pengujian antar tiap titik $1 \mathrm{~mm}$.

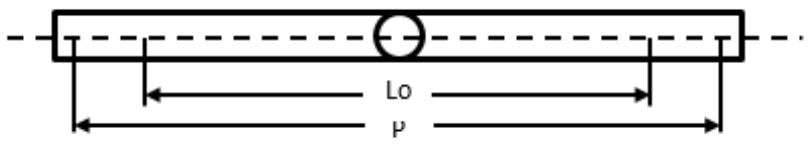

Gambar 5. Penampang kawat

\section{HASIL PENELITIAN}

Hasil pengujian makro dan mikrostruktur memperlihatkan terjadinya perbedaan jenis/ ukuran struktur mikro dan fasa yang terbentuk dan dinyatakan dengan warna kontras, terutama antara weld metal dengan daerah HAZ (Heat Affected Zone) sangat jelas perbedaannya yang dipisahkan oleh batas las. Ukuran butir terbesar terdapat pada daerah weld metal kemudian berubah semakin halus setelah melewati HAZ kemudian base metal.

Foto makro pada gambar 7 menunjukkan pada daerah weld metal (lihat gambar 6) terlihat jelas batas butir, dengan bentuk butir bulat besar. Memasuki daerah $H A Z$ bentuk butir berubah memanjang hal ini dikarenakan selama proses pengelasan mengalami siklus thermal pemanasan dan pendinginan cepat sehingga akan terjadi kombinasi antara pembentukan butir-butir yang kasar sebagai akibat terekspos pada suhu tinggi dengan timbulnya transformasi fasa, dari fasa padat ke fasa padat lain (Suratman, 2011).

Foto makro hasil lasan juga dapat terlihat cacat-cacat yang terjadi pada hasil lasan yaitu cacat porositas seperti ditunjukkan pada Gambar 7. Cacat porositas ini terbentuk pada daerah weld metal, cacat porositas pada hasil lasan ini disebabkan oleh terperangkapnya gas hidrogen pada saat pembekuan, hal ini terjadi dikarenakan gas hidrogen memiliki kelarutan tinggi dalam aluminium cair tetapi sangat rendah dalam padat. Karena batas kelarutan turun pada waktu pendinginan maka gas hidrogen keluar dari larutan dan karena proses pembekuan yang cepat menyebabkan gas ini terperangkap dan membentuk gelembung halus (Wiryosumarto dan Okumura, 2000).

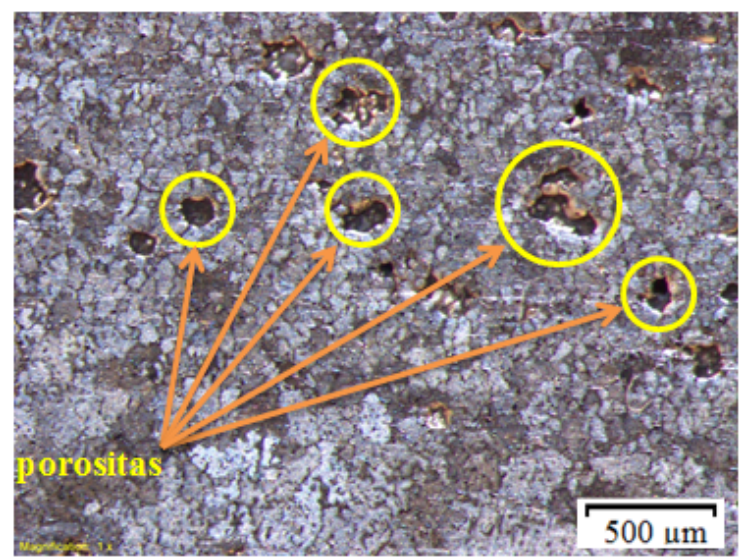

Gambar 6. Cacat porositas pada weld metal

Cacat porositas ini umumnya bulat, terisolasi dan terdistribusi merata pada daerah weld metal dengan ukuran yang bervariasi, ratarata ukuran lubang halus porositas yang didapati sekitar $140 \mu \mathrm{m}$, yang termasuk dalam macroporosity karena berukuran lebih dari $100 \mu \mathrm{m}$ (Akhtar, 2010). Porositas merupakan penyebab utama dalam penurunan sifat mekanik, terutama elongation dan fatigue resistance (Bangyikhan, 
2005). Adanya cacat porositas ini dapat menyebabkan turunnya kekuatan pada daerah weld metal bila dibandingkan dengan base metal yang tidak terdapat porositas.

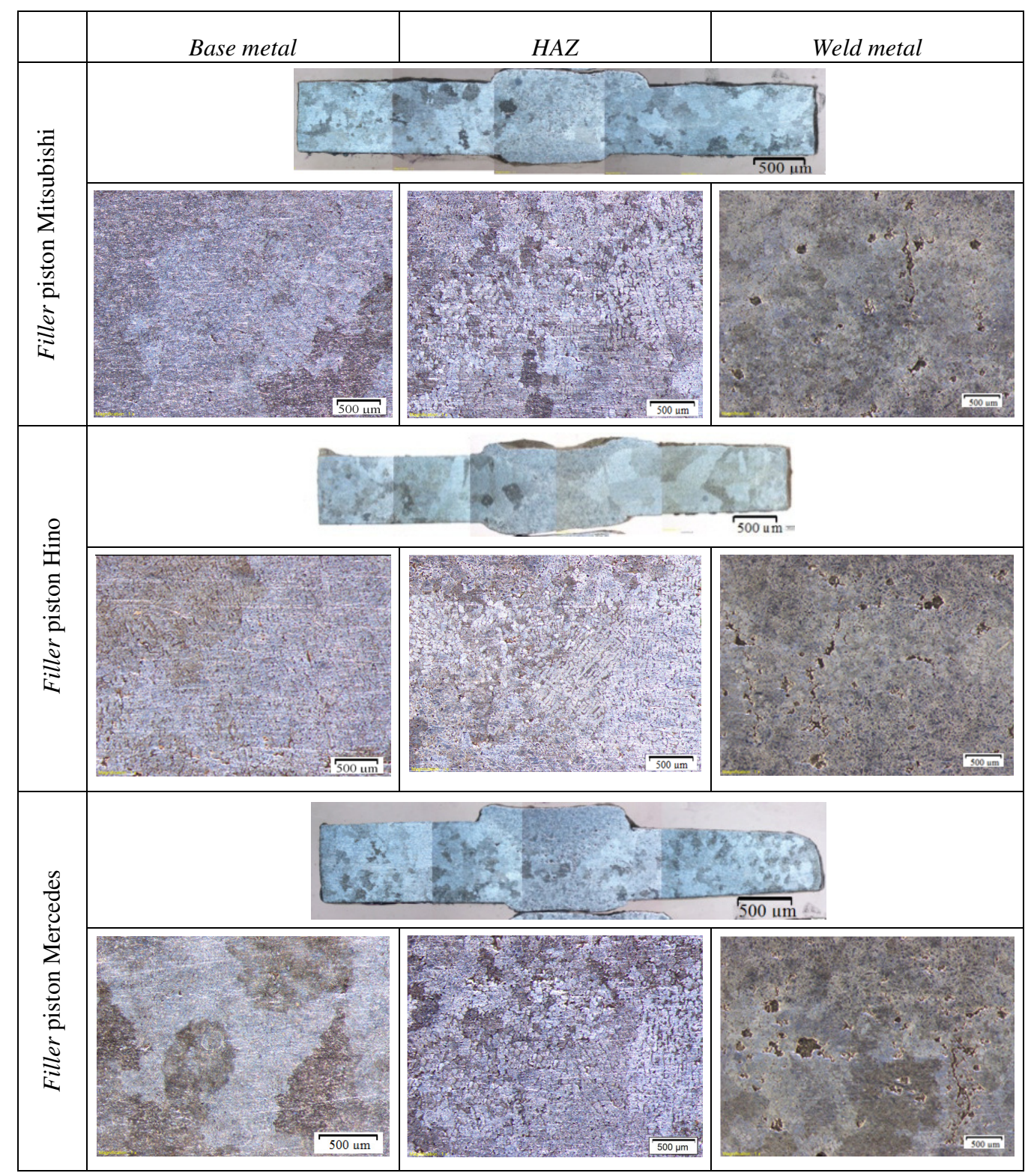

Gambar 7. Foto struktur makro hasil lasan.

Kekerasan base metal permukaan material umumnya lebih tinggi, hal ini disebabkan sebaran unsur Si yang lebih merata pada base metal karena daerah ini cenderung tidak terpengaruh oleh panas yang dihasilkan selama proses pengelasan. Hal tersebut dibuktikan dengan terdapatnya nilai kekerasan tertinggi pada daerah weld metal yaitu sebesar $124 \mathrm{HVN}$. Memasuki daerah $H A Z$ kekerasan cenderung turun jauh sebesar 73,4 HVN yang tercatat sebagai nilai kekerasan terendah pada hasil lasan menggunakan filler piston mercedes, turunnya nilai kekerasan ini disebabkan oleh berkurangnya sebaran Si dikarenakan pada daerah $H A Z$ ini tidak mencair tetapi sudah mengalami pengaruh perubahan mikrostruktur akibat pemanasan dan 
pendinginan selama proses pengelasan dengan saling mengikatnya Si pada daerah tersebut, sehingga struktur yang dihasilkan berupa unsur Si yang menjadi membesar dan tidak merata.

Pada daerah weld metal terjadi kenaikan nilai kekerasan dengan besaran yang bervariasi, tetapi tidak sampai melebihi kekerasan base metal, naiknya nilai kekerasan ini dipengaruhi oleh butiran unsur Si yang lebih kecil dan bertebaran pada matrik Al secara merata. Nilai kekerasan tertinggi pada daerah weld metal ini terdapat pada hasil lasan dengan filler Hino sebesar 107,2 HVN seperti ditunjukan pada gambar 8 . Umumnya nilai kekerasan dipengaruhi sebaran Si pada matrik Al, semakin meratanya sebaran Si maka kekerasan semakin tinggi, sebaliknya jika sebaran Si tidak merata dan ukuran butir Al membesar maka kekerasannya akan menurun (Abdillah, 2010).

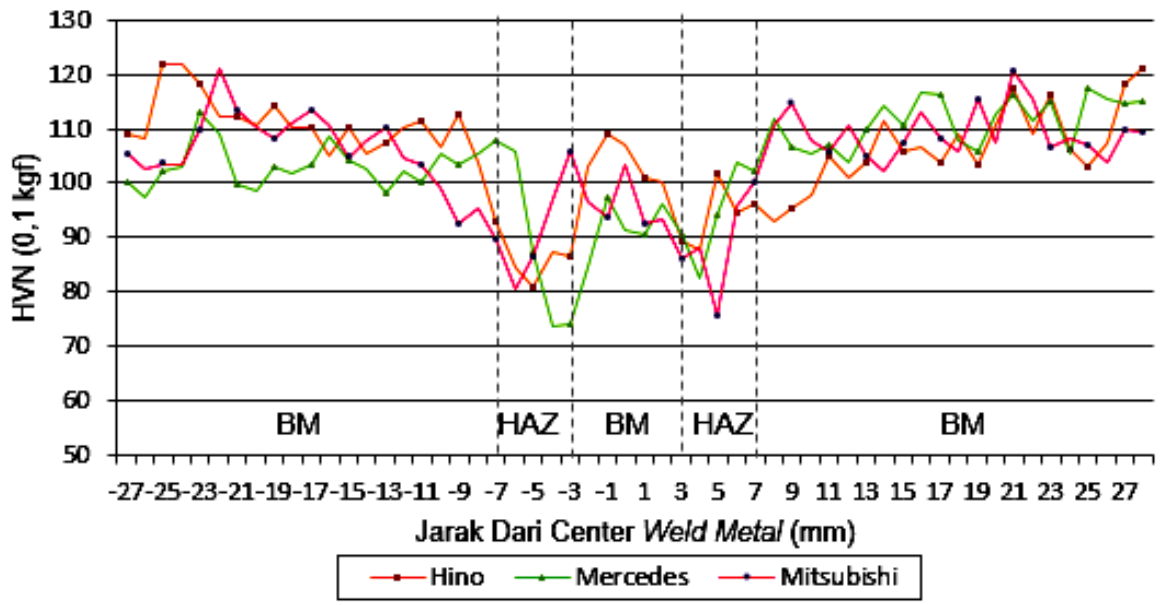

Gambar 8. Distribusi kekerasan pada hasil lasan antar variasi filler.

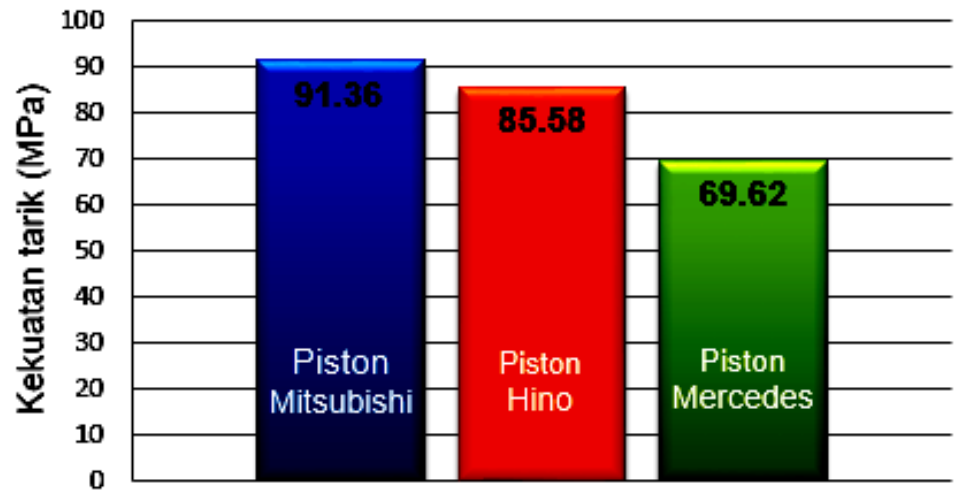

Jenis filler

Gambar 9. Hasil uji tarik lasan.

Hasil uji tarik memperlihatkan variasi filler Mitsubishi memiliki rata-rata kekuatan tarik tertinggi sebesar 91,36 Mpa, gambar 9. Variasi filler Hino memiliki rata-rata kekuatan tarik sebesar 85,58 Mpa. Variasi filler Mercedes Benz memiliki rata-rata kekuatan tarik terendah sebesar 69,92 Mpa. Patahan yang dihasilkan keseluruhan merupakan patah getas, yaitu jenis patahan berbentuk rata dan mengkilat, apabila potongan disambung potongannya tidak dimuati dengan deformasi plastis.
Umumnya patahan terjadi pada daerah $H A Z$ apabila hasil pengelasan sempurna tanpa adanya cacat, akan tetapi apabila hasil pengelasan terdapat cacat porositas pada weld metal maka patahan akan terdapat daerah tersebut (Liu et al., 2003). Patah pada daerah weld metal ini dapat disebabkan oleh faktor struktur mikro pada weld metal ataupun karena faktor proses pengelasan. Faktor struktur mikro yang mempengaruhi yaitu adanya porositas pada daerah weld metal, sehingga mengakibatkan konsentrasi pembebanan pada uji tarik terpusat pada daerah weld metal. 
Patahan hasil uji tarik tersebut diteliti lebih lanjut untuk memastikan patahan berada pada daerah weld metal dengan melakukan foto makro

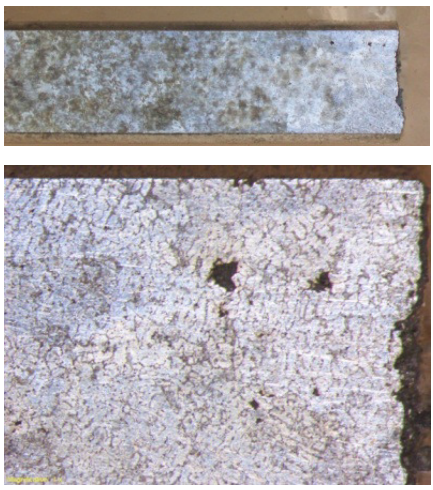

Filler piston Mitsubishi

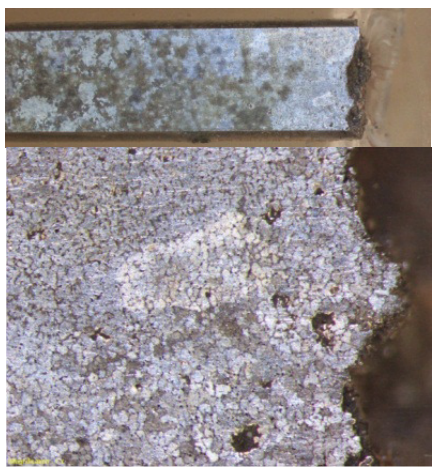

Filler piston Hino

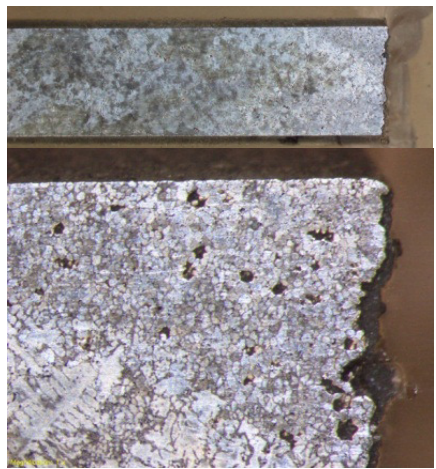

Filler piston Mercedes Benz

Gambar 10. Foto makro penampang melintang patahan uji tarik.

Porositas dipengaruhi oleh kadar tembaga (Cu) yang terkandung dalam paduan aluminium, bahwa meningkatnya kadar tembaga menaikkan besarnya porositas yang dihasilkan selama pengelasan (Shabestari and Moemeni, 2004). Kenaikan porositas ini disebabkan oleh dua hal. Pertama, unsur tembaga menyebabkan reaksi eutektik terner pada suhu $525^{\circ} \mathrm{C}$. Tingginya kandungan tembaga pada titik cair eutektik meningkatkan penyusutan volumetrik selama pembekuan dan timbulnya porositas. Kedua, koefisien aktivitas hidrogen menurun dengan meningkatnya kadar tembaga dan terjadi penurunan kelarutan hidrogen. Oleh karena itu, porositas terbentuk dengan cepat selama pembekuan pada paduan yang mengandung tembaga (Edwards et al., 1997). Komposisi kimia filler Mercedes memiliki prosentase $\mathrm{Cu}$ 1,26\% yang merupakan prosentase tertinggi dari variasi filler yang lainnya, sehingga pada hasil lasan terdapat banyak porositas yang menyebabkan kekuatannya paling rendah. Kekuatan tarik terbesar terdapat pada hasil lasan dengan filler piston mitsubishi, karena filler piston mitsubishi memiliki prosentase $\mathrm{Cu}$ yang paling rendah yaitu $1,08 \%$, sehingga hasil lasannya juga minim porositas.

\section{KESIMPULAN}

Kekuatan tarik tertinggi hasil pengelasan diperoleh oleh sambungan las dengan menggunakan filler piston mitsubishi, karena piston mitsubishi memiliki komposisi kimia yang hampir sama dengan blok mesin. Patah uji tarik terjadi pada daerah weld metal dikarenakan adanya cacat porositas sehingga pembebanan uji tarik terkonsentrasi pada cacat tersebut. Cacat porositas yang terbentuk dipengaruhi oleh prosentase $\mathrm{Cu}$ pada material filler dimana semakin tingi prosentase $\mathrm{Cu}$ maka cacat porositas yang terbentuk semakin banyak.

\section{DAFTAR PUSTAKA}

Abdillah F., 2010, Perlakuan panas paduan Al-Si pada prototipe piston berbasis material piston bekas, Program Studi Magister Teknik Mesin, Universitas Diponegoro Semarang.

Akhtar S.H., 2010, Hydrogen porosity in Al-Si foundry alloys, Department of Materials Science and Engineering, Norwegian University of Science and Technology.

Bangyikhan K., 2005, Effects of oxide film, fe-rich phase, porosity and their interactions on tensile properties of cast Al-Si-Mg alloys, School of Metallurgy and Materials, The University of Birmingham.

Edwards G.A., Sigworth G.K., Cacers C.H., John D.H.St., Barresi J., 1997, Microporosity formation in $\mathrm{Al}-\mathrm{Si}-\mathrm{Cu}-\mathrm{Mg}$ casting alloys, AFS Trans.

Liu H.J., Fujii H., Maeda M., Nogi K., 2003, Tensile properties and fracture locations of frictionstir-welded joints of 2017-T351 aluminum alloy, Journal of Materials Processing Technology, 142, 692-696.

Shabestari S.G., Moemeni H., 2004, Effect of copper and solidification conditions on the microstructure and mechanical properties of $\mathrm{Al}-\mathrm{Si}-\mathrm{Mg}$ alloys, Journal of Materials Processing Technology, 153-154.

Sudargo P.H., Triyono, Diharjo K., 2011, Pengaruh filler dan arus listrik terhadap sifat fisikmekanik sambungan las gmaw logam tak 
sejenis antara baja karbon dan J4, Pasca Sarjana Jurusan Teknik Mesin, Universitas Sebelas Maret Surakarta.

Suratman R., 2011, Beberapa kasus pada pengelasan, API-IWS, http://www.apiiws.org/beberapa-kasus-pada-pengelasan. html.
Turan E., Kocal T., Ünlungencoglu K., 2011, Welding technologies in shipbuilding industry, The Online Journal of Science and Technology, 1(4).

Wiryosumarto H., Okumura T., 2000, Teknologi pengelasan logam, PT. Pradnya Paramita, Jakarta. 